\title{
Olhar a COVID-19 em São Tomé e Príncipe
}

\author{
Flávio Castelo David dos Santos Andrade ${ }^{1,2}$ (iD) \\ 'Quadro do Ministério da Saúde "Programa de Saúde Mental"; \\ ${ }^{2}$ Faculdade de Ciências e das Tecnologias da Universidade de São Tomé e Príncipe (FCT-USTP). \\ $\checkmark$ davidflacas25@hotmail.com
}

Recebido em: 10 setembro 2020; Revisto em: 26 setembro 2020; Aceite em: 02 outubro 2020

\section{Resumo}

Introdução: Este trabalho teve como objectivo conhecer o percurso, e a existência da COVID-19 em São Tomé e Príncipe. Os documentos utilizados foram boletim diário da COVID-19, Decreto, extratos das conferências de impressa, plano de contingência. A metodologia adotada é qualitativa e as técnicas utilizadas foram pesquisa documental para recolha de informações e a análise documental para tratamento. Os resultados apontam a existência da COVID-19 em São Tomé e Príncipe, observa-se também que os primeiros casos importados da COVID-19 entraram e circularam em finais do mês de fevereiro. Conclui-se que em 21 de abril ocorreu o primeiro surto em dois distritos, em 30 de abril, primeiro óbito (um homem de 55 anos), e 13 óbitos entre abril e junho. Por fim ressalta-se que necessário se torna realizar um estudo para compreender a imunidade a COVID-19 nesta parcela do mundo.

Palavras-chave: COVID-19, pandemia, santomenses, São Tomé e Príncipe, saúde.

\section{INTRODUÇÃO}

Os primeiros relatos de infeção pelo novo coronavírus começaram a surgir a 31 de dezembro de 2019, a China reportou à Organização Mundial da Saúde (OMS) um "cluster" de pneumonia de etiologia desconhecida em trabalhadores e frequentadores de um mercado de peixe, mariscos vivos e aves na cidade de Wuhan, província de Hubei, na China. Em 9 de janeiro de 2020, as autoridades chinesas identificaram um novo vírus da família dos coronavírus (2019-nCoV), como agente causador da doença (Freitas, 2020).

Mais adiante Freitas (2020) realça que a transmissão pessoa-pessoa, através de gotículas está confirmada (...), o impacto potencial de epidemia por SARS-CoV-2 é elevado, sendo expectável a propagação global do vírus. Por isso mesmo, em 30 de janeiro de 2020, o Diretor-geral da OMS declarou a doença por novo coronavírus como uma Emergência de Saúde Pública de Âmbito Internacional (Ibid, 2020).

Segundo o Centre D'Études Stratégiques de l'Afrique CESA (2020) a África anunciou o seu primeiro caso do novo coronavírus, ou COVID-19, em 15 de fevereiro de 2020, dois meses depois de ter sido identificado pela primeira vez na China. $\mathrm{O}$ vírus agora está presente em cada um dos 54 países da África.

Em São Tomé e Príncipe (STP), podemos situar dois momentos que marcam o início da história da COVID-19, a saber: legislativo e registo dos primeiros casos. O primeiro ocorre em meado do mês de março de 2020, altura em que foram tornados público os primeiros normativos no âmbito desta problemática. Assim, desde o dia 17 do supracitado mês que a sociedade são-tomense dispõe de informações que the permite apreender a magnitude dos problemas relacionados

1 Conglomerados, agregados, agrupamentos - termo que designa um conjunto de casos, grupos ou eventos que parecem relacionar-se pela sua forma de

distribuição no espaço e /ou no tempo. com a pandemia da COVID-19. Pois é no primeiro Decreto n. ${ }^{\circ}$ 3/2020, onde o Presidente da República Evaristo Carvalho decretou o seguinte:

É declarado o Estado de emergência em saúde pública, em todo o território nacional decorrente do surto de coronavírus (COVID-19), tendo em vista a necessidade do emprego urgente de medidas de prevenção, controlo e prevenção de riscos, danos e agravos à saúde pública (STP, 2020).

O segundo momento, cuja importância interessa realçar e assinalar, ocorre em dia 6 de abril de 2020, data histórica nacional e internacional, quando São Tomé e Príncipe, entra no mapa dos países com a pandemia da COVID-19, altura em que o Primeiro-ministro anunciou ao povo santomense e ao mundo que os testes enviados a Franceville - Gabão, 4 casos são considerados positivos da COVID-19.

\section{DO CASO IMPORTADO AO CENÁRIO ATUAL DA COVID-19 EM SÃO TOMÉ E PRÍNCIPE}

\subsection{CASO IMPORTADO}

O primeiro aspeto que caracteriza a pandemia da COVID-19 no território santomense está relacionado com a pista da negligência para detetar o caso importado, isto é, o sistema nacional de saúde, desprovido de especialistas em diversas áreas da saúde, neste caso particular de epidemiologista de formação superior, não conseguiu focar os seus holofotes para conhecer o supracitado caso. Tal como Amado (2020) realça que:

O sistema de saúde são-tomense precisa de ser profundamente reformulado. Temos que começar pela formação dos profissionais de saúde, que precisam de fazer especialidades médicas (médicos), reciclagens permanentes (enfermeiros, analistas e demais pessoal técnico), mais formação (pessoal administrativo), melhor formação (todos os outros funcionários e pessoal de apoio). 
Quem terá sido o caso importado da COVID-19 no território santomense? Pergunta cuja resposta até hoje é uma incógnita. Enquanto arquipélago, STP tem como porta de entrada da COVID-19, a via aérea, uma vez que não temos ligações marítimas internacionais de passageiros, parecia que reuníamos todas as condições naturais e geográficas, para controlar e identificar o caso importado ${ }^{2}$ no território nacional. A identificação do caso

2 Caso que foi exposto a um determinado agente etiológico da infecção ou doença em causa, fora do país onde se encontra (Freitas, G., 2020, p. i)". importado no território santomense permitiria isolá-los e evitar a expansão da COVID-19. Tal como Freitas (2020) defende que a "identificação precoce de casos e surtos é fundamental para interromper as cadeias de transmissão e limitar a transmissão comunitária".

Em suma, como só foram suspensos todos os voos comerciais e privados de São Tomé e do Príncipe para o exterior e vice-versa, pelo Decreto Presidencial n. ${ }^{\circ}$ 4/2020, do dia 2

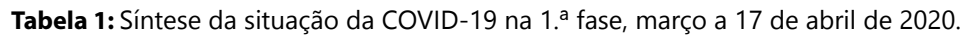

\begin{tabular}{|c|c|c|c|c|c|}
\hline Casos confirmados & Suspeitos & Sob investigação & Internado & Casos recuperados & Óbitos \\
\hline 4 & $\begin{array}{c}\text { Não se tornou } \\
\text { público }\end{array}$ & $\begin{array}{c}\text { Não se tornou } \\
\text { público }\end{array}$ & 0 & $\begin{array}{c}4 \text { - mas sem do diagnóstico } \\
\text { evidências científicas }\end{array}$ & 0 \\
\hline
\end{tabular}

de abril, conduz-nos a afirmar hipoteticamente que o caso importado da COVID-19 entrou entre os meses de fevereiro a abril, circulou e saiu do país.

\subsection{INCAPACIDADE DE DIAGNÓSTICO}

O segundo grande aspeto que sinaliza a pandemia no território santomense é a inaptidão de diagnóstico, bem como as formas com que as autoridades e a população lidaram com a COVID-19 em diferentes momentos. No nosso entender, podemos dividir este período do novo coronavírus em STP em

Tabela 2: Síntese da situação da COVID-19 na 2. ${ }^{a}$ fase, até ao 21de abril de 2020.

\begin{tabular}{|c|c|c|c|c|c|}
\hline Casos confirmados & Internado & Casos recuperados & Óbitos & $\begin{array}{c}\text { País do diagnóstico \& Tipo } \\
\text { de teste }\end{array}$ & Tipo \& Local de tratamento \\
\hline 3 casos & 3 & $\begin{array}{c}4 \text { - mas sem } \\
\text { evidências científicas }\end{array}$ & 0 & $\begin{array}{c}\text { São Tomé e Príncipe / Testes } \\
\text { rápidos }\end{array}$ & $\begin{array}{c}\text { Convencional/ Hospital Ayres de } \\
\text { Menezes }\end{array}$ \\
\hline
\end{tabular}

três fases: $\mathbf{a}, \mathbf{b}$ e $\mathbf{c}$.

Fase a. Testagem das amostras pelos laboratórios internacionais de países amigos e circunjacentes, com resultados a partir de 26 de março a 17 de abril de 2020 .

Esta fase inicia-se com os resultados dos três grupos de testes enviados a diferentes países e laboratórios de referência a nível internacional, quer europeu (Portugal), como africanos (Gabão e Guiné Equatorial), todos com resultados já conhecidos, negativos (26 de março de 2020), 4 positivos e os restantes negativos (6 de Abril de 2020), e 79 negativos e um caso inconclusivo (17 de Abril de 2020).

A primeira observação que parece ser possível fazer desta

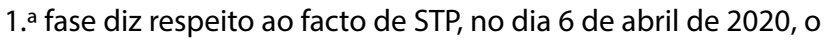
Primeiro-ministro Jesus, numa conferência de imprensa, declara

Tabela 3: Síntese da situação da COVID-19 na 3. ${ }^{a}$ fase, até o dia 24 de junho de 2020.

\begin{tabular}{|c|c|c|c|c|}
\hline Casos confirmados & Casos em isolamento domiciliar & Internado no hospital de campanha & Casos recuperados & Óbitos \\
\hline 710 & 483 & 3 & 211 & 13 \\
\hline
\end{tabular}

que são diagnosticados 4 primeiros casos da COVID-19, dentre os que encontravam em quarentena no hotel e domiciliar. Onze (11) dias depois estes são dados como recuperados, isto é, no dia 17 do mesmo mês, o que fez com que STP regressasse à lista de países sem casos da COVID-19; entre 17 a 21 de abril, estes 4 dias constituíram o início da desconfiança da população em torno da existência da COVID-19 no nosso país.

Fase b. Realização de testes rápidos em São Tomé e Príncipe, com resultados a partir 21 de abril. Esta fase iniciase 15 dias depois do diagnóstico dos primeiros 4 casos, altura em que Ministro da Saúde Neves, declara, no dia 21 de abril, o diagnóstico de 3 casos positivos, sendo 2 do distrito de Água Grande e 1 do Mé-Zóchi, todos do sexo masculino, e sem ligações com os primeiros 4 casos, o que nos leva a concluir que estávamos diante do primeiro surto da COVID-19 no território santomense.
A tabela acima exposta espelha o facto de que até ao dia 21 de abril, existiam 3 casos confirmados da COVID-19, mas sem percebermos a cadeia de contágio.

Fase c. Testagem pelo PCR, no território de STP, com resultados a partir do dia 24 de junho. Esta fase que vai de 21 de abril a 24 de junho, por um lado iniciou com a notificação do primeiro óbito no dia 30 de abril (um homem de 55 anos), por outro lado contempla duas grandes acções do governo para mitigar o progresso da pandemia, isto é, inauguração do Hospital de Campanha para os doentes da COVID-19, no dia 20 de maio e inauguração do laboratório PCR, no dia 24 de junho.

Tanto falado e esperado, o laboratório PCR, no arquipélago santomense estreia com 10 teste PCR, sendo 6 negativos e 4 positivos, dos quais, 3 são casos novos, cf. Boletim do dia 24 de Abril. 


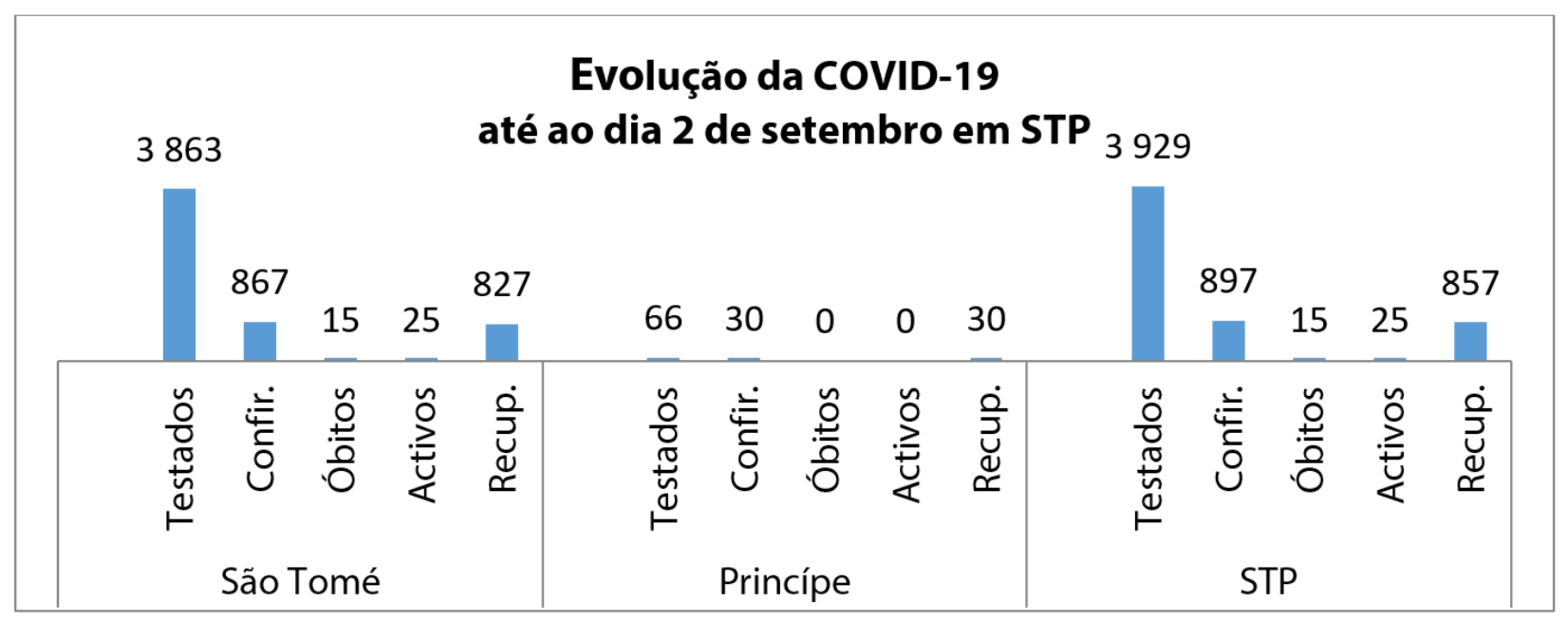

Gráfico 1: Síntese da evolução da COVID-19 entre março e 2 setembro de 2020.

Em traços gerais, percebe-se que em dois meses, isto é, entre 21 de abril a 24 de junho, STP registou um total de 13 óbitos e 211 casos recuperados.

\subsection{CENÁRIO ATUAL DA COVID-19 EM SÃO TOMÉ E PRÍNCIPE}

O terceiro aspeto que sinaliza a pandemia é o seu cenário atual em STP, hoje é visível uma descida de números de casos da COVID-19, o que tem levado a redução de uso das máscaras, ao aumento de pequenas concentrações das pessoas, ao regresso massivo a praias e início do ano letivo 2020-2021. Em suma, parece existir uma imunidade adquirida na população santomense. Segundo o boletim diário da COVID-19, n. ${ }^{\circ} 131$ de 03 de setembro de 2020, referente ao dia 2 de setembro, dos 54 testes PCR realizados, 51 foram negativos e 3 positivos, dos quais 1 caso novo. Mais adiante constatamos que foram confirmados 897 casos da COVID-19 positivos acumulados e 857 casos recuperados. No Hospital de Campanha encontra-se 1 doente internado, 24 casos positivos em isolamento domiciliar e finalmente mantém-se os 15 óbitos.

Neste domínio, Anne Ancia, atual representante da OMS em STP, durante uma cerimónia no Ministério da Saúde, no dia 28 de agosto, declarou que STP, "está no fim da fase aguda da epidemia da COVID-19, ou seja, estamos a entrar numa fase de consolidação". Mais adiante a mesma acrescenta que "neste momento estamos a trabalhar com o Ministério da Saúde, no desenvolvimento de uma estratégia de busca ativa de casos da COVID-19 nas comunidades".

O gráfico acima visível reflete o facto de que a Região Autónoma do Príncipe até o dia 2 de setembro, não apresentava óbitos, nem casos ativos, enquanto São Tomé, já tinha 15 óbitos e 25 casos ativos. Percebe-se ainda que em STP existiam 897 confirmados e 857 recuperados, bem como 15 óbitos da COVID-19.

\section{CONCLUSÕES}

Concluímos que as autoridades responsáveis pela saúde santomense não conseguiram identificar o caso importado da COVID-19, nem tão pouco a sua cadeia de transmissão inicial, o que nos transporta a concluir que o caso entrou e circulou no país, em finais do mês de fevereiro.
O mês de abril marca o ponto mais alto, faz notícias no país e fora dele, em volta da COVID-19; em 6 de abril, registaram-se os primeiros 4 casos positivos, em 17 de abril são dados como recuperados os supracitados casos, em 21 de abril, o primeiro surto em dois distritos, em 30 de abril, primeiro óbito (um homem de 55 anos), e acresce a todos esses factos o registo de 13 óbitos entre abril e junho.

Conclui-se ainda que a ausência de recursos humanos especializados para o laboratório PCR e para o programa de vigilância epidemiológica, bem como a falta de seguranças nas autoridades responsáveis pela saúde, pôs a nu os serviços da saúde em geral e, em particular, os cuidados primários de saúde e lançou as bases de desconfiança da população em não acreditar na existência da COVID-19 no território santomense.

Portanto, há mais de um mês, ou seja, desde 29 de julho que não se regista mais óbitos pela COVID-19 no território santomense, e o número de casos novos oscilam entre 0-2 casos, o que nos transporta a afirmar que entramos numa fase de estabilização ou mesmo de recuperação uma vez que a atividade da doença decresce em STP.

Em suma, propomos a realização de uma investigação que permitiria fornecer evidências científicas, por um lado, para percebermos a causa do baixo número de casos confirmados e, por outro, o elevado número de recuperados da COVID-19 em STP.

\section{REFERÊNCIAS BIBLIOGRÁFICAS}

Amado, L.N., Redacção hoje apetece-me fazer uma redacção. Julho, 2020. Disponível em (https://www.telanon.info/suplemento/ opiniao/2020/07/14/32150 /redaccao-hoje-apetece-me-fazeruma-redaccao. Consultado em 06-08-2020.

Ancia, Anne. (2020, agosto, 28). Durante uma cerimónia no Ministério da Saúde, dada a Televisão São-tomense (TVS).

Andrade, F.C.D.S., 4-Casos positivos em São Tomé e Príncipe \& Agora? Abril, 2020. Disponível em https://www.telanon.info/suplemento/ Opinião/2020/04/15/31519/covid-19-4-casos-positivos-em-saotome-e-principe-agora/. Consultado em 08-08-2020.

Andrade, F.C.D.S., Covid-19 as principais etapas em São Tomé e Príncipe. Abril, 2020. Disponível em https://www.telanon.info/suplemento/ opiniao/2020/04/23/31557/covid-19-as-principais-etapas-emsao-tome-e-principe/. Consultado em 10-08-2020.

Centre D'Études Stratégiques de I'Afrique (CESA)., O Coronavírus se espalha na África. Agosto, 2020. Disponível em https://africacenter. 
org/fr/spotlight/le-

coronavirus-se-repand-en-afrique/.

Consultado em 17-08-2020.

Freitas, Graça (Ed.)., Plano Nacional de Preparação e resposta à doença por novo coronavírus (COVID-19). 2020. Disponível em https:// www.dgs.pt/.documentos-e-publicacoes/plano-nacional-depreparacao-e-resposta-para-a-doenca-por-novo-coronaviruscovid-19-pdf.aspx. Consultado em 10-04-2020.

Jesus, J.B. (2020, Abril, 06). Conferência de imprensa, dada a Televisão São-tomense (TVS).

Jesus, J.B.\& Neves, E. (2020, Abril, 17). Conferência de imprensa, dada a Televisão São-tomense (TVS).

Ministério da Saúde (2020). COVID-19 | Portal. Disponível em covid. ms.gov.st/st/. Consultado em 31-08-2020.

Neves, E. (2020, Abril, 21). Conferência de imprensa dada a Televisão São-tomense.

São Tomé e Príncipe - Diário da República N. 9 - 18 de Março de 2020. Decreto Presidencial n. $3 / 2020$.

São Tomé e Príncipe - Diário da República N. 15 - 2 de Abril de 2020. Decreto Presidencial n. 0 4/2020.

São Tomé e Príncipe - Boletim Diário Coronavírus COVID-19 do dia 24de Junho de 2020.

São Tomé e Príncipe - Boletim Diário Coronavírus COVID-19 do dia 11de Agosto de 2020.

São Tomé e Príncipe - Boletim Diário Coronavírus COVID-19 n. ${ }^{\circ}$ 131, do dia 03 de Setembro de 2020. 